University of Wollongong

Research Online

Faculty of Social Sciences - Papers (Archive) Faculty of Arts, Social Sciences \& Humanities

2016

Social climate profiles in adolescent sports: Associations with enjoyment and intention to continue

Lauren Gardner

University of Wollongong, lag994@uowmail.edu.au

Christopher A. Magee

University of Wollongong, cmagee@uow.edu.au

Stewart A. Vella

University of Wollongong, stvella@uow.edu.au

Follow this and additional works at: https://ro.uow.edu.au/sspapers

Part of the Education Commons, and the Social and Behavioral Sciences Commons

Research Online is the open access institutional repository for the University of Wollongong. For further information contact the UOW Library: research-pubs@uow.edu.au 


\title{
Social climate profiles in adolescent sports: Associations with enjoyment and intention to continue
}

\begin{abstract}
This study explored whether adolescent sports participants' perceptions of the social climate fall into distinct profiles, and whether these profiles are related to enjoyment and intention to continue. A Latent Profile Analysis using 313 Australian sports participants $(M$ age $=13.03$ years) revealed four distinct profiles: positive social climate $(45.1 \%)$, diminished social climate $(19.8 \%)$, positive coach relationship quality (19.8\%), and positive friendship quality (15.3\%). Individuals within the positive social climate and the positive coach relationship quality profiles reported relatively higher levels of enjoyment and intention to continue than individuals in the diminished social climate and the positive friendship quality profiles. Indirect path analyses found the social climate profiles were linked with intention to continue through enjoyment. Results highlight the value of investigating multiple dimensions of the social climate and suggest that the coach may be of particular importance in this age group. Findings have implications for understanding youth sports participation and preventing dropout.
\end{abstract}

\section{Keywords}

sports, associations, enjoyment, intention, continue, climate, adolescent, profiles, social

\section{Disciplines}

Education | Social and Behavioral Sciences

\section{Publication Details}

Gardner, L. A., Magee, C. A. \& Vella, S. A. (2016). Social climate profiles in adolescent sports: Associations with enjoyment and intention to continue. Journal of Adolescence, 52 112-123. 


\section{Abstract}

2 This study explored whether adolescent sports participants' perceptions of the social climate

3 fall into distinct profiles, and whether these profiles are related to enjoyment and intention to

4 continue. A Latent Profile Analysis using 313 Australian sports participants $\left(M_{\text {age }}=13.03\right.$

5 years) revealed four distinct profiles: positive social climate (45.1\%), diminished social

6 climate (19.8\%), positive coach relationship quality (19.8\%), and positive friendship quality

7 (15.3\%). Individuals within the positive social climate and the positive coach relationship

8 quality profiles reported relatively higher levels of enjoyment and intention to continue than

9 individuals in the diminished social climate and the positive friendship quality profiles.

10 Indirect path analyses found the social climate profiles were linked with intention to continue

11 through enjoyment. Results highlight the value of investigating multiple dimensions of the

12 social climate and suggest that the coach may be of particular importance in this age group.

13 Findings have implications for understanding youth sports participation and preventing

14 dropout. 
Social Climate Profiles in Adolescent Sports: Associations with Enjoyment and Intention to Continue

Understanding how aspects of the social climate - defined by the influence of key social figures (namely parents, coaches, and peers) - influence sports participation is valuable given that sports participation during childhood and adolescence has consistently been linked with positive health outcomes (Eime, Young, Harvey, Charity, \& Payne, 2013; Ntoumanis \& Biddle, 1999). For example, sports participation has been linked with a range of positive physical and psychosocial health outcomes including reduced rates of overweight and obesity, improved social skills, resilience, greater self-esteem, improved emotional regulation, fewer mental health problems, and less problem behaviors (Eime et al., 2013; Hebert, Møller, Andersen, \& Wedderkopp, 2015; Janssen \& Leblanc, 2010). Notably, the psychosocial health benefits associated with sports participation surpass those attributable to unstructured physical activity alone (Eime et al., 2013; Vella, Cliff, Magee, \& Okely, 2015). Additionally, research shows that sports participants experience less psychological difficulties and greater health-related quality of life compared to individuals who drop out or do not participate in sport (Vella, Cliff, Magee, \& Okely, 2014; Vella et al., 2015). The purpose of the current study is to investigate how individual differences in perceptions of key social relationships are associated with youth sports participation.

\section{The Social Climate and Adolescent Sport}

Parents represent a key component of the social climate as they play a vital role in early sports participation where they are responsible for introducing children to their chosen sport and providing ongoing support (Côté, 1999; Fredricks \& Eccles, 2005). Parental support can include tangible support (e.g., financial costs and transport), socio-emotional support (e.g., encouragement and aiding understanding), informational support (e.g., explaining the rules), and companionship (e.g., watching sports events) (Côté, 1999; Côte \& 
Hay, 2002). Parental support has been linked with a range of important psychological and behavioral outcomes in youth sports. For example, children who perceive their parents to be more supportive tend to experience greater enjoyment, intrinsic motivation, and are more likely to continue participating in sport (Atkins, Johnson, Force, \& Petrie, 2013; Sheridan, Coffee, \& Lavallee, 2014). However, parents can also have negative influences. For example, parental pressure is one of the most common interpersonal reasons for youth sports dropout (Crane \& Temple, 2015). Therefore, gaining an understanding of perceptions of parental support could provide valuable information in regards to adolescent sports participation and dropout.

Coaches are often considered to play a similar role to parents given their position of authority and responsibility to provide support. However, the role of a coach is different as they are also relied upon for technical instruction to aid skill development (Côté \& Gilbert, 2009; Keegan, Spray, Harwood, \& Lavallee, 2010). Positive coach-athlete relationships represent a key component of the social climate because they have been linked with a number of motivational outcomes including increased motivation and greater persistence in youth sports (Gould, Collins, Lauer, \& Chung, 2007; Riley \& Smith, 2011). High quality coachathlete relationships are characterized by high perceptions of closeness (e.g., feelings such as respect, trust, and appreciation), commitment (e.g., intentions to maintain the relationship), complementarity (e.g., the cooperative and reciprocal behaviors), and co-orientation (e.g., perceptions about shared views and common ground) (Jowett \& Ntoumanis, 2004; Jowett \& Poczwardowski, 2007). However, research suggests that the coach-athlete relationship is commonly implicated in the decision to withdraw from youth sports (Rottensteiner, Konttinen, \& Laakso, 2015). Contributing factors may include coach conflict, a controlling and autocratic coaching style, lack of encouragement, and an overemphasis on winning (Gearity \& Murray, 2011; Gould, 2007; Pelletier, Fortier, Vallerand, \& Brière, 2001). It is 
therefore important to understand the role of coaches, and more specifically the coach-athlete relationship, in the context of youth sports participation and dropout.

Peers represent another core component of the social climate in the context of youth sport. The role of peers is very different to that of parents and coaches, and has received relatively less empirical attention (Keegan, Harwood, Spray, \& Lavallee, 2009; Smith, Ullrich-French, Walker, \& Hurley, 2006). The two main dimensions of peer relationships that tend to be targeted in youth sports research are peer acceptance and friendship quality (Smith et al., 2006). Peer acceptance refers to popularity and liking by the larger peer group, whereas friendship quality refers to having a close and reciprocated dyadic relationship (Bukowski \& Hoza, 1989). From a developmental perspective, Sullivan (1953) argued that the two dimensions make distinct contributions yet they can also compensate for other relationship shortcomings. For example, it is theorized that a close and high quality friendship may buffer against the negative outcomes associated with low peer acceptance (Smith, 1999; Sullivan, 1953). Additionally, Ullrich-French and Smith (2006; 2009) found peer acceptance and friendship quality to be uniquely and positively associated with enjoyment and continuation in soccer. Therefore, given that these dimensions have distinct influences on motivational outcomes in youth sport, they both need to be considered (Smith, 1999; Ullrich-French \& Smith, 2006). This may be particularly salient when the two facets of peer relationships are functioning at different levels as they could have an interactive effect.

\section{Key Motivational Outcomes in Youth Sports}

Enjoyment and intention to continue are two key motivational processes that could influence participation and dropout in youth sports (Balish, McLaren, Rainham, \& Blanchard, 2014; Crane \& Temple, 2015). Sports enjoyment refers to a positive emotional response acquired from the sports experience (Scanlan \& Simons, 1992). Enjoyment has consistently been linked with continued participation, whereas lack of enjoyment is reported to be the 
single most common reason for dropout in youth sports (Crane \& Temple, 2015; Gould, 2007). Intentions refer to an individual's motivation and plans for future behavior (Ajzen, 1991) and have been shown to directly predict actual sports behaviors, including participation and dropout (Balish et al., 2014). Although a number of other factors may contribute to continued participation in youth sports, the consistent findings in the youth sports literature linking enjoyment and intention to continue with participation suggests that the two factors are particularly important to future sports participation behavior (Balish et al., 2014; Crane \& Temple, 2015). Furthermore, according to research using behavioral change theories such as the theory of planned behavior, the self-determination theory, and achievement goal theory, both factors should be considered because enjoyment can be conceptualized as an antecedent of intention (Ajzen \& Driver, 1992; Atkins, Johnson, Force, \& Petrie, 2015; Quested et al., 2013). This suggests that enjoyment could have an indirect effect on sports participation through its influence on intentions to continue.

Although these theories suggest that components of the social climate could influence sports participation via their effects on the motivational processes outlined above, few studies have examined all three key figures in the social climate. Available studies have tended to focus narrowly on the motivational climates created by parents, coaches, and peers (Atkins et al., 2015; Chan, Lonsdale, \& Fung, 2012; Sarrazin, Vallerand, Guillet, Pelletier, \& Cury, 2002). The motivational climate refers to the perception that social agents are promoting an environment for effort and learning (i.e., a task-involving climate) or emphasizing success in comparison to others (i.e., an ego-involving climate) (Ames, 1992). This research indicated task-involving motivational climates from parents, coaches, or peers are associated with greater enjoyment and in turn greater intention to continue. That is, perceiving parent, coach, and peer behaviors to be supportive and encouraging of effort and improvement, despite 
setbacks, resulted in greater levels of enjoyment and intention to continue in sport (Atkins et al., 2015).

However, the motivational climate is just one dimension contributing to perceptions of the social climate, and research may benefit from looking at other types of relationships comprising the wider social climate (Hall, Newland, Newton, Podlog, \& Baucom, 2016).

This is because other facets of relationships may be associated with youth sports participation independently. For example, studies investigating the coach created motivational climate tend to focus on coach behaviors, rather than the coach-athlete relationship, and although both factors share some of the explained variance in athlete outcomes, they have also been shown to make unique contributions (Rottensteiner et al., 2015; Vella, Oades, \& Crowe, 2013).

Given that factors such as parental support and the coach-athlete relationship have been shown to contribute to the formation of the motivational climate (Atkins et al., 2013; Olympiou, Jowett, \& Duda, 2008), it might be expected that perceptions of parental support, coach-athlete relationship, friendship quality, and peer acceptance will influence outcomes in a similar fashion to motivational climates. However, the unique differences in the types of relationships may yield some important and novel findings.

\section{Social Climate Profiles}

Along with a dearth of research investigating the perceived influence of the social climate in youth sports, previous research has not examined whether combinations of social relationships are related to motivational outcomes. Instead, existing studies have tended to examine the influence of parents, coaches, and peers on motivational outcomes independently. This overlooks the potential co-occurrence of relationships with parents, coaches, and peers, the nature of which could considerably vary between individuals and could have important implications for motivation in sport. 
Although some studies have attempted to look at combinations of relationships in youth sports (e.g., Smith et al., 2006; Ullrich-French \& Smith, 2006), these investigations only included elements of peer and/or parental relationships. Nevertheless, this research has shown that the effects of social relationships are not isolated and they can influence sports motivation in an additive and collective way (Ullrich-French \& Smith, 2009). Additionally, different relationships may fulfill both similar and different developmental needs (Furman \& Buhrmester, 1985), and examining combinations of relationships may provide more information about the relative influence of each social figure. For example, the aforementioned research by Ullrich-French and Smith (2006; 2009) found that high peer acceptance and friendship quality led to a high probability of continuation even when the quality of the mother relationship was low. However, a high quality mother relationship predicted continuation regardless of the levels of the peer relationships. This finding may suggest that parents and coaches remain the most significant social figures during childhood and early adolescence, whereas peers become increasingly influential during later adolescence (15-18 years) (Chan et al., 2012). Furthermore, Smith et al. (2006) created peer relationship profiles which demonstrated that combinations of peer relationship perceptions are salient to motivation-related variables. For example, the greatest enjoyment was reported by individuals within the profile characterized by high peer acceptance and friendship quality with relatively low conflict, as well as those within the profile characterized by high friendship quality, peer acceptance, and conflict. In contrast, less enjoyment was reported by individuals within the profile characterized by relatively low levels of each variable, as well as the profile characterized by relatively low peer acceptance and conflict with average friendship quality. These findings suggest that relationships with social figures are complex and there is a need to further investigate how distinct profiles of social relationships are associated with sports participation. 


\section{Summary and Study Aims}

The current research adopts a person-centered approach (using latent profile analysis) to investigate whether there are distinct social climate profiles reflecting the level of support and quality of relationships with parents, coaches, and peers. We then investigate whether these social climate profiles are associated with enjoyment and intention to continue.

It is hypothesized that there will be individual differences in the type and level of perceived social climates across multiple sources of relationships among adolescent sports participants, and that those individual differences will have implications for enjoyment and intention to continue. Specifically, we expect a profile characterized by more positive perceptions of relationships with parents, coaches, and peers will be associated with greater enjoyment and intention to continue, whereas a profile characterized by less positive perceptions of relationships will be associated with lower enjoyment and less intention to continue. These associations are expected to occur in an additive and collective fashion. It is also hypothesized that certain social climate factors will interact with one another. For example, given the prominent role of parents and coaches in youth sports participation and enjoyment (Chan et al., 2012; Ullrich-French \& Smith, 2009), profiles characterized by positive perceptions of parental support and/or coach-athlete relationship quality will be expected to experience high enjoyment and intention to continue even when friendship quality and peer acceptance are low. Additionally, given that a high quality friendship is theorized to negate the effects of low peer acceptance (Smith, 1999; Sullivan, 1953), a profile characterized by high friendship quality should be associated with enjoyment and intention to continue despite low levels of peer acceptance. Finally, given that enjoyment is theorized to precede intention, it is expected that the social climate profiles will be linked with intention to continue indirectly through enjoyment. 
A number of variables that may confound the aforementioned relationships will be controlled for in the analyses. Firstly, age will be included because the influence of key social figures on motivational outcomes has been found to vary as sports participants progress through childhood and adolescence. For example, parents may be most influential during childhood whereas peers may become more important during later adolescence (Chan et al., 2012). Gender has also been linked with varying relationships. For example, it has been suggested that a high quality friendship may be more important for participation among females than it is for males (Smith et al., 2006). The number of years of participation will be included given that the importance of enjoyment for continued participation may vary based on the stage of participation the individual is at. For example, enjoyment may be more important for continued participation during the initial years than it is after a number of years of participation when the individual is likely to have a greater investment in the sport (Côté, Baker, \& Abernethy, 2003). Lastly, the type of sport will be included given that team and individual sports have been related to different psychosocial outcomes and the influence of key social figures may be vary between them (Eime et al., 2013).

\section{Method}

\section{Participants and Procedures}

A total of 393 students (94 males, 299 females) from private high schools in the New South Wales region of Australia took part in the study. The 327 students who identified as regular sports participants (i.e., participated in organized sports one to three times per week for at least three months over the past year) were included in the study. Data were inspected for univariate outliers using boxplots which indicated the existence of outliers for each of the social variables (parental support, coach-athlete relationship quality, friendship quality, and peer acceptance). Data were also screened for multivariate outliers using Mahalanobis distance; however, none of the cases exceeded the critical value $(p<.001)$. Following the 
removal of outliers, the remaining 313 regular sports participants (75 males, 238 females) ranged from 11 to 15 years of age, with a mean age of 13.03 years $(S D=.84)$. The participants most commonly described their ethnic background as Oceanian $(n=85,27.2 \%)$, Southern and Eastern European $(n=81,25.9 \%)$, and North-West European $(n=45,14.4 \%)$. One hundred and eighty-six participants (59\%) reported their main sport to be a team sport, and 127 (41\%) participants reported their main sport to be an individual sport. Of the 25 different sports that were reported, the most common team sports were soccer $(n=62$, 19.8\%) and netball $(\mathrm{n}=51,16.3 \%)$, and the most common individual sports were dancing ( $\mathrm{n}$ $=43,13.7 \%)$ and swimming $(\mathrm{n}=26,8.3 \%)$. The participants indicated that they had been participating in their main sport for an average of 5.48 years $(S D=3.03)$, trained an average of 2.77 days per week $(S D=1.31)$, and were most commonly participating at the basic competition level $(\mathrm{n}=171,54 \%)$. The study was approved by the institutional research ethics committee. Participants completed questionnaires during their regular Physical Education lesson.

\section{Measures}

Enjoyment. The Enjoyment subscale from the Sport Commitment Model (SCM; Scanlan, Simons, Carpenter, Schmidt, \& Keeler, 1993) was used to assess enjoyment in sport. Four items (e.g., 'Do you like playing your main sport?') were rated on a five point scale ranging from 1 (not at all) to 5 (very much). Cronbach's alpha in the current study was $\alpha=$ .96, with similar levels reported in previous youth sports research (Atkins et al., 2015).

Intention to continue. To assess intention to continue, participants responded to one item ('I intend to participate in my main sport next season') which was rated on a five-point scale ranging from 1 (strongly disagree) to 5 (strongly agree).

Perceived Parental Support in Sport. The Perceived Parental Support Scale (PPSS; Van Yperen, 1995) was used to assess sport specific perceived parental support. The scale 
consists of four items (e.g., 'If I have a problem, my parents will help me’) rated on a fivepoint scale ranging from 1 (strongly disagree) to 5 (strongly agree). Participants were instructed to answer each item with respect to their main sport. The scale has demonstrated validity and reliability in the youth sport context (Lafferty \& Dorrell, 2006). In the present study the Cronbach's alpha coefficient was $\alpha=.78$.

Perceived Friendship Quality in Sport. Perceived friendship quality in sport was assessed using the Sport Friendship Quality Scale (SFQS; Weiss \& Smith, 1999). The scale consists of 22 items assessing six dimensions of friendships; self-esteem enhancement and supportiveness (e.g., 'My friend gives me a second chance to perform a skill'), loyalty and intimacy (e.g., 'My friend and I stick up for each other in sports'), things in common (e.g., 'My friend and I do similar things'), companionship and pleasant play (e.g., 'My friend and I spend time together'), conflict resolution (e.g., 'My friend and I make up easily when we have a fight'), and conflict (e.g., 'My friend and I fight'). Participants were instructed to think about their closest friend in their main team or sport and rated their responses on a five-point scale ranging from 1 (not at all true) to 5 (really true). Cronbach's alpha in the current study was $\alpha=.90$.

Perceived Peer Acceptance in Sport. The Social subscale of the Self-Perception Profile for Children (Harter, 1985) was used to assess peer acceptance in sport. The scale consists of six items adapted to be specific to sports. Items were presented in a structuredalternative format (e.g. 'Some kids are popular in their team/sport but other kids are not very popular in their team/sport'). Participants were instructed to decide which statement is most like them with respect to their main sport, and then indicate whether the statement is 'really true for me' or 'sort of true for me'. In the present study the Cronbach's alpha coefficient was $\alpha=.82$ 

answer each item with respect to their coach in their main sport. The items tap into three subscales: Closeness (e.g., 'I trust my coach’), Commitment (e.g., 'I feel committed to my coach’), and Complementarity (e.g., 'When I am coached by my coach, I feel responsive to shown to be highly related, a composite score of the three subscales was used to indicate an overall perception of the quality of the coach-athlete relationship (Adie \& Jowett, 2010; Lafrenière, Jowett, Vallerand, \& Carbonneau, 2011). In the current study, the correlations between the three subscales ranged between .83 and .85 . The CART-Q has demonstrated high levels of validity and reliability (Jowett \& Ntoumanis, 2004). Cronbach’s alpha in the current study was $\alpha=.94$.

Covariates. Participants’ age, gender, number of years of participation, and type of sport were included as covariates in the analyses.

\section{Design/Statistical Analysis}

Descriptive statistics were produced using IBM SPSS statistics software (version 21).

Given the different scales and number of items in each of the measures, scores for parental support, coach-athlete relationship quality, friendship quality, and peer acceptance were standardized into z-scores for ease of interpretation of the distinct profiles. A latent profile analysis (LPA) was performed using Mplus version 7 (Muthén \& Muthén, 1998-2012) to identify distinct profiles of individuals based on individual differences in perceived relationships with parents, coaches, and peers. The optimal number of latent profiles was informed by several statistical criteria. The Akaike’s Information Criteria (AIC), Bayesian 
Information Criteria (BIC), and sample-size adjusted BIC were examined, with lower values indicating a better model fit. Classification accuracy (entropy) and the size of the latent profiles were also considered. Although there are no clear cut-offs for entropy, values much lower than .80 should be treated with caution, since lower values indicate a lack of clear separation between two or more profiles (Celeux \& Soromenho, 1996). Bootstrap likelihood ratio tests (BLRTs) were used to compare the fit between two consecutive models. A significant BLRT result indicates that the model with $k$ profiles (e.g., four latent profiles) provides a better fit compared to a model with $k-1$ profiles (e.g., three latent profiles). The ideal number of profiles is achieved when the BLRT is no longer significant; this indicates that the model with $k-1$ latent profiles is considered optimal (Nylund, Asparouhov, \& Muthen, 2007). In addition to the statistical criteria, the profiles were inspected to ensure they were meaningful, distinct, and not merely variations on a theme (Ram \& Grimm, 2009). Age, gender, number of years of participation, and type of sport were included as covariates.

To assess whether the profile groups differed on levels of enjoyment and intentions to continue, two separate general linear models were analyzed with Bonferroni corrected posthoc pairwise comparisons. Age, gender, number of years of participation, and type of sport were controlled for in the analyses.

Finally, an indirect path model was tested to examine whether the social climate profiles were linked with intention to continue via enjoyment. The social climate profiles were dummy coded with the largest profile (the positive social climate profile) functioning as the reference category. Therefore, the direct ( $c^{\prime}$ paths) and indirect effects ( $a b$ paths) are considered relative to this group (Hayes \& Preacher, 2014). The direct effect refers to the association between the dependent variable (Y) and the independent variable (X) while accounting for the mediator (M). The indirect effect refers to the pathway from $\mathrm{X}$ to $\mathrm{Y}$ through M. A bootstrapping procedure with 10,000 resamples was used to test the relative 
indirect effects with statistical significance determined on the basis of 95\% confidence intervals. Results are reported in terms of standardized $(\beta)$ regression coefficients. Age, gender, number of years of participation, and type of sport were specified as covariates on both M (enjoyment) and Y (intention to continue) (Hayes \& Preacher, 2014).

\section{Results}

\section{Descriptive Statistics}

The descriptive statistics for the study variables are presented in Table 1. Participants perceived high levels of parental support, moderate-to-high coach-athlete relationship quality, high friendship quality, moderate-to-high peer acceptance, high enjoyment and high intention to continue. Bivariate Pearson’s correlations revealed that all study variables were significantly and positively correlated.

\section{Latent Profile Analyses}

The results of the LPA are presented in Table 2. The four profile model provided a better model fit compared with the preceding models. The five profile model had a statistically improved model fit according to the AIC and sample-size adjusted BIC; however, the BLRT results indicated that the difference between the model with five profiles and the model with four profiles was not significant. Additionally, the four profile model represented a more conceptually sound and parsimonious solution than the five profile model which separated one distinct profile into two overlapping profiles, one of which had a very small sample size. Therefore, the model with four latent profiles was considered optimal in this study. The average probabilities for most likely latent variable membership for the four profiles ranged between .83 and .91 . These profiles are illustrated in Figure 1 and the means and standard deviations of social variables by profile are presented in Table 3. It is important to note that the sample reported high levels of parental support, coach-athlete relationship quality, friendship quality, and peer acceptance. Therefore, to facilitate the interpretation of 
the data, the constructs and labels are discussed in relative terms and they are not intended to represent the profiles in absolute terms. For example, the profile with the lowest score for parental support still exhibits a score greater than the midpoint of the perceived parental support scale; however, the profile has the lowest score relative to the other three profiles. We therefore consider this profile to be relatively low on parental support. This technique has been employed in previous studies as it is a common issue in youth sports research (Smith et al., 2006).

The most common profile ( $\mathrm{n}=141 ; 45.1 \%$ ) was characterized by the highest levels of perceived parental support, coach-athlete relationship quality, friendship quality, and peer acceptance. As a result, this profile was labeled positive social climate.

The second profile ( $\mathrm{n}=62 ; 19.8 \%$ ) was characterized by relatively low levels of parental support, coach-athlete relationship quality, friendship quality, and peer acceptance. Therefore, this profile was labeled diminished social climate.

The third profile $(n=62 ; 19.8 \%)$ was characterized by relatively low levels of parental support and peer acceptance with the most distinguishing features being the relatively high levels of coach-athlete relationship quality and relatively low levels of friendship quality. Therefore, this profile was labeled positive coach relationship quality. The fourth profile ( $n=48 ; 15.3 \%$ ) was characterized by relatively low levels of parental support and peer acceptance with the most distinguishing features being the relatively high levels of friendship quality and relatively low levels of coach-athlete relationship quality. This profile was therefore labeled positive friendship quality. Levels of parental support and peer acceptance did not differ significantly between the positive friendship quality profile and the positive coach relationship quality profile.

\section{Group Differences in Enjoyment and Intentions to Continue}



$\eta^{2}=.19$, and intention to continue, $F(3,312)=10.64, p<.001, \eta^{2}=.09$, when controlling for age, gender, number of years of participation, and type of sport. In regards to enjoyment, the Bonferroni corrected post-hoc pairwise comparisons showed that the positive social climate profile $(M=19.60, S D=1.14)$ did not significantly differ from the positive coach relationship quality profile $(M=19.23, S D=1.41)$. However, individuals in both the positive social climate profile and the positive coach relationship quality profile reported significantly more enjoyment than the positive friendship quality profile $(M=17.44, S D=3.29)$ and the diminished social climate profile $(M=17.16, S D=3.20)$. The positive friendship quality profile and the diminished social climate profile did not differ significantly from each other. Similarly for intentions to continue, individuals in the positive social climate profile $(M=4.79, S D=.57)$ and the positive coach relationship quality profile $(M=4.58, S D=.78)$ reported significantly greater intention to continue than those in the diminished social climate profile $(M=4.15, S D=.96)$. However, only individuals in the positive social climate profile reported significantly greater intention to continue than those in the positive friendship quality profile $(M=4.37, S D=.87)$.

Indirect Path Analysis

The model linking the three social climate profiles with intention to continue through enjoyment, relative to the positive social climate profiles is shown in Figure 2. When controlling for age, gender, number of years of participation, and type of sport, the diminished social climate profile $\left(a_{1}\right)$, the positive coach relationship quality profile $\left(a_{2}\right)$, and the positive friendship quality profile $\left(a_{3}\right)$ were associated with relatively less enjoyment than the positive social climate profile. However, only the diminished social climate profile $\left(c^{\prime}{ }_{1}\right)$ and the positive friendship quality profile $\left(c_{3}^{\prime}\right)$ had a significant direct effect on intention to continue. Enjoyment was positively associated with intention to continue $\left(b_{1}\right)$. Compared to 
the positive social climate profile, the diminished social climate profile $\left(a_{1} b_{1}\right), \beta=-.18,95 \%$ CI [-.56, -.19], the positive coach relationship quality profile $\left(a_{2} b_{2}\right), \beta=-.03$, [-.13, -.005], and the positive friendship quality profile $\left(a_{3} b_{3}\right), \beta=-.14$, [-.50, -.18], were indirectly linked to lower intentions via lower levels of enjoyment.

\section{Discussion}

To our knowledge, the current study is the first to explore whether there are individual differences in the type and level of perceived social climates in adolescent sports based on relationships with parents, coaches, and peers. This is important given that the social climate has been strongly associated with children's involvement in youth sports, which in turn has been linked with a range of positive health outcomes (Eime et al., 2013). The LPA identified four distinct social climate profiles: positive social climate (45.1\%), diminished social climate (19.8\%), positive coach relationship quality (19.8\%), and positive friendship quality (15.3\%). The study also sought to explore whether these profiles are associated with motivational outcomes including enjoyment and intention to continue in sport. Consistent with expectations, individuals characterized by a positive social climate profile reported the greatest enjoyment and intention to continue, whereas individuals characterized by a diminished social climate profile reported relatively less enjoyment and intention to continue. Interestingly, individuals in the positive coach relationship quality profile also reported relatively high levels of enjoyment and intention to continue, despite lower levels of parent and peer relationships; these findings may indicate that the coach plays a key role in adolescent sports participation. Finally, as expected, the social climate profiles were found to be indirectly linked with intentions to continue through enjoyment compared to the positive social climate profile.

Results support previous research demonstrating that more positive perceptions of relationships with parents, coaches, and peers are associated with greater enjoyment in youth 
sports (Sánchez-Miguel, Leo, Sánchez-Oliva, Amado, \& García-Calvo, 2013; Scanlan, Carpenter, Lobel, \& Simons, 1993; Smith et al., 2006). This is also consistent with previous assertions that multiple positive social relationships will be associated with more positive motivational outcomes (Ullrich-French \& Smith, 2009). However, the finding that the highest levels of enjoyment were also observed in the positive coach relationship quality profile (characterized by relatively high levels of coach-athlete relationship quality coupled with relatively low levels of friendship quality), whereas relatively less enjoyment was observed in both the diminished social climate profile and the positive friendship quality profile (characterized by relatively high levels of friendship quality coupled with relatively low levels of friendship quality), suggests that the quality of the coach-athlete relationship may be of particular importance to enjoyment in youth sports. This is consistent with previous findings demonstrating that a positive coach-athlete relationship is associated with positive motivational outcomes in youth sports (Gould et al., 2007; Riley \& Smith, 2011;

Rottensteiner et al., 2015; Vella et al., 2013), and that coach support and satisfaction are stronger predictors of youth sports enjoyment than peer and parental support (Scanlan, Carpenter, et al., 1993).

The findings also suggest that perceived friendship quality, when coupled with relatively low levels of coach-athlete relationship quality, parental support, and peer acceptance, is of less importance to adolescent sports participants' enjoyment in this age group. This is counter to previous research emphasizing the role of positive peer relationships in sports enjoyment (Scanlan, Carpenter, et al., 1993; Smith et al., 2006), and our hypothesis that friendship quality can buffer against the negative effects of low peer acceptance (Sullivan, 1953). However, Sullivan’s (1953) theory only considered the two aspects of peer relationships and it is possible that the lower levels of parental support and coach-athlete relationship quality may override the protective effect. Additionally, Chan et al. (2012) found 
that age moderated the association between social influences and motivational outcomes among a sample of 9 to 18 year old swimmers. Specifically, the role of peers was most important for enjoyment between the ages of 15 and 18 years, whereas coaches and parents were most important prior to this age. This suggests that the sports participants in the current research may still be most responsive to the influence of their coach and parents, as compared to their peers. However, the finding that parental support was not a salient variable in any of the profiles is in line with previous research suggesting that parents are most influential during the childhood years (Chan et al., 2012).

Additionally, the findings support the co-occurrence of social relationships but highlight that individuals can experience different combinations of relationships which may uniquely contribute to motivational outcomes in youth sport. Given that social figures may exert different influences, it is possible that some supportive social relationships compensate for a lack of support from other relationships. This is in line with previous developmental theory proposing a compensatory model of social relationships (Furman \& Buhrmester, 1985). Therefore in the current study, although this did not occur in the positive friendship quality profile, the finding that the positive coach relationship quality profile maintained the greatest levels of enjoyment and intention to continue, despite poorer perceptions of parent and peer relationships, suggests that coach relationships serve a compensatory function in youth sport. This may be because coach relationships fulfill similar needs to that which parents and peers do, and therefore act as an alternative source when those relationships are lacking (Wiese-Bjornstal, Lavoi, \& Omli, 2009). For example, similar to parents, coaches are authority figures who can fulfill the adolescents' needs for socio-emotional and informational support (Côté \& Hay, 2002; Keegan et al., 2010; Wiese-Bjornstal et al., 2009). Additionally, coaches can provide a close dyadic relationship in the sporting context which could be considered similar to the role of friendship quality in sport (Bukowski \& Hoza, 1989; Wiese- 
Bjornstal et al., 2009). Therefore, the results may not be signifying that parental support and friendship quality are not important; rather, they may be highlighting the importance of the coach-athlete relationship which can act as a surrogate source of these relationships. A close friendship in sport alone may not be sufficient to address the needs usually fulfilled by parents and/or coaches for the positive friendship quality group.

To our knowledge, the current study is the first to examine the link between intentions to continue and the social climate based on perceptions of relationships with all three social figures. Given that intentions are considered to be closely linked with actual behaviors (Ajzen \& Driver, 1992), the finding that less positive perceptions of relationships with parents, coaches, and peers are independently associated with less intention to continue is in line with previous dropout research (Balish et al., 2014; Crane \& Temple, 2015). Although research investigating all three social figures simultaneously has looked specifically at motivational climates in relation to both enjoyment and intention to continue, none of the motivational climates were directly related to intention to continue. Instead, the task-involving motivational climates were indirectly associated with intention to continue through enjoyment (Atkins et al., 2015). The difference between the findings in regards to perceptions of the motivational climate and the direct perceptions of relationships in the current study may highlight the importance of investigating other types of relationships contributing to the wider social climate. This is further evidenced by inconsistent findings regarding enjoyment where parent and/or peer created motivational climates were found to be more influential than coach created motivational climates (Atkins et al., 2015; Chan et al., 2012). Therefore, as in some previous research (e.g., Rottensteiner et al., 2015), future research might benefit from including both direct perceptions of relationships as well as motivational climates with all three social figures to examine their unique and relative influence on motivational outcomes in youth sport. 
profile also reported relatively less intention to continue, whereas those in the positive social

climate and positive coach relationship quality profiles reported high intention to continue.

Again, this may be suggesting that the coach-athlete relationship is particularly important

whilst deemphasizing the importance of perceived friendship quality, or highlighting the compensatory nature of social relationships. However, given that the positive coach relationship quality profile and the positive friendship quality profile did not differ significantly from one another, this notion appears more tenuous in regards to intentions to continue. This is an interesting finding given that enjoyment and intention to continue or drop out have consistently been linked in youth sports research (Atkins et al., 2015). It is possible that the use of a multi-item scale to measure enjoyment, as opposed to a single-item scale to assess intention to continue, produces a more reliable measure and allows for more distinguishable results (Nunnally, 1978). Additionally, there may be fundamental differences between the nature of intentions and enjoyment in this context. For example, according to the Theory of Planned Behavior (Ajzen \& Driver, 1992), intentions are influenced by perceived social norms, perceived behavioral control, and attitudes toward the behavior. In contrast, support from key social figures along with effort and mastery have been identified as the major sources of youth sports enjoyment (Scanlan, Carpenter, et al., 1993). Therefore, the direct relationship between aspects of the social climate and enjoyment may have led to greater sensitivity to differences in the profiles, as compared to intention to continue. This is further supported by the finding that the social climate profiles were indirectly linked with intentions through enjoyment. Therefore, in line with previous behavioral change theories,

507 the two outcomes can be ordered, with enjoyment preceding intentions (Atkins et al., 2015;

508 Quested et al., 2013).

509 Practical Implications 
The use of a person-centered approach to identify distinct profiles of individuals may

511

512

513

514

515

516

517 enable researchers to identify individuals at risk of negative outcomes, such as dropout, and develop intervention strategies tailored to address their specific issues. For example, the finding that individuals who perceive a high quality coach-athlete relationship experienced the greatest enjoyment and intentions to continue, despite having relatively low levels of parental support, friendship quality, and peer acceptance, suggests that the coach-athlete relationship is of significant value. Therefore, researchers might target this relationship to potentially prevent outcomes including dropout. For example, coach education programs could be developed to teach coaches strategies and techniques that facilitate high quality relationships with athletes. These may include communication skills, team building activities, positive reinforcement and feedback, developing trust, goal setting, being responsive and supportive, and how to appropriately discipline athletes (Camiré, Forneris, Trudel, \& Bernard, 2011; Gould et al., 2007).

Although the present research suggests that the coach-athlete relationship may be of particular importance, relationships with parents and peers in youth sport should not be discounted. Findings demonstrated that distinct combinations of interpersonal relationships are associated with motivational outcomes in youth sports, and support the notion that some positive relationships can compensate for other less positive relationships (Furman \& Buhrmester, 1985). It is therefore important that the collective influence of all three social figures be considered in future research to enable a more comprehensive understanding of the youth sports experience. Future research might also benefit from looking at more specific variables, such as relationships with mothers and fathers separately, or the influence of peers outside the sports context (i.e., perceived behavioral norm).

\section{Limitations and Future Directions}


A limitation of the current research is the cross-sectional nature of the data as it does

535

536

537

538

539

540

541

542

543

544

545

546

547

548

549

550

551

552

553

554

555

556

557

558 not allow us to draw conclusions about causality or directionality. For example, we are

unable to determine whether individuals experience greater enjoyment and intention to

continue because of their high quality relationship with their coach, or whether it is because they enjoy the sport and want to continue participating that they actively seek out and build positive relationships with their coach. Future research should incorporate longitudinal designs to explore this, along with actual dropout behavior.

Other limitations include the relatively small percentage of variance explained by the profiles and the entropy level in the latent profile analysis falling short of the recommended level of .80 (Celeux \& Soromenho, 1996) which may reflect issues of distinctiveness.

However, the entropy value of .75 is not substantially lower than the recommendation and indicates fairly good separation between the profiles. Furthermore, other statistical criteria including the results of the BLRT and the average probabilities for most likely latent variable membership support the retained profiles. Research utilizing more detailed measures of social relationships may result in profiles that better distinguish between individuals. Additionally, the levels of enjoyment and intention to continue within the sample were not normally distributed. The sample reported high levels of both variables which indicates the existence of ceiling effects. This is a common issue in youth sports research given that individuals generally participate in their sport voluntarily so are expected to have high levels of motivation (Smith et al., 2006). Although the results and profiles are explained in relative terms, rather than absolute terms, when we consider the profiles with the lowest enjoyment and intention to continue, it is important to remember that they do not necessarily have low levels of enjoyment and intention to continue in absolute terms.

The current research also utilizes participants aged 11 to 15 years, which is a fairly wide age range in this context. For example, previous research revealed age effects during 
adolescence with the importance of parents, coaches, and peers varying as sports participants progress through childhood and adolescence (Chan et al., 2012). Future research with larger sample sizes would allow for specific age effects to be examined which could provide further insights into the links between social relationships and sport participation in children and adolescents. Another limitation is that participants were recruited from two private high schools and therefore are of relatively high socioeconomic status. This is important given that socioeconomic factors have been found to be predictors of sports participation and dropout (Vella, Cliff, \& Okely, 2014). This is reflected in the high percentage of participation reported within the sample. Therefore, the study should be replicated in a sample incorporating participants from a range of socioeconomic positions and from a greater number of schools which enables the use of a clustered design. Furthermore, this research should consider other factors implicated in youth sports participation, such as parental pressure, as participation may not always be completely voluntary for youth sports participants (Friedman, 2013). The sample was also skewed towards females. Future research should aim to include a more even spread of males and females, or investigate each gender separately. Nevertheless, key strengths of the study include the incorporation of all three social figures and the use of latent profile analysis which is an improvement on other previously used statistical techniques such as cluster analysis (Pastor, Barron, Miller, \&

Davis, 2007).

\section{Conclusion}

The results of this study revealed that individual differences in perceptions of the social climate, based on relationships with parents, coaches, and peers, exist and fall into distinct profiles which are associated with varying levels of enjoyment and intention to continue in sport. Additionally, the social climate profiles were linked with intention to continue indirectly through enjoyment. Results highlight the importance of investigating 
584 combinations of relationships with the three key social figures in youth sports. The findings

585 suggest that the coach-athlete relationship may be of particular importance and may

586 compensate for a lack of other supportive relationships in this age group. Findings could have

587 important implications for understanding youth sports participation and dropout, which in

588 turn could aid in improving physical and psychosocial health outcomes among children and

589 adolescents. 
591

592

593

594

595

596

597

598

599

600

601

602

603

604

605

606

607

608

609

610

611

612

613

Adie, J. W., \& Jowett, S. (2010). Meta-perceptions of the coach-athlete relationship, achievement goals, and intrinsic ,motivation among sport participants. Journal of Applied Social Psychology, 40, 2750-2773. doi: 10.1111/j.1559-1816.2010.00679.x

Ajzen, I. (1991). The theory of planned behavior. Organizational Behavior and Human Decision Processes, 50, 179-211.

Ajzen, I., \& Driver, B. L. (1992). Application of the theory of planned behavior to leisure choice. Journal of Leisure Research, 24, 207-224.

Ames, C. (1992). Achievement goals, motivational climate, and motivational processes. In G. C. Roberts (Ed.), Motivation in sport and exercise (pp. 161-176). Champaign, IL: Human Kinetics.

Atkins, M. R., Johnson, D. M., Force, E. C., \& Petrie, T. A. (2013). "Do I still want to play?" Parents' and peers' influences on girls' continuation in sport. Journal of Sport Behavior, 36, 329-345.

Atkins, M. R., Johnson, D. M., Force, E. C., \& Petrie, T. A. (2015). Peers, parents, and coaches, oh my! The relation of the motivational climate to boys' intention to continue in sport. Psychology of Sport and Exercise, 16, 170-180. doi: 10.1016/j.psychsport.2014.10.008

Balish, S. M., McLaren, C., Rainham, D., \& Blanchard, C. (2014). Correlates of youth sport attrition: A review and future directions. Psychology of Sport and Exercise, 15, 429439. doi: 10.1016/j.psychsport.2014.04.003

Bukowski, W. M., \& Hoza, B. (1989). Popularity and friendship: Issues in theory, measurement, and outcome. In T. J. Berndt \& G. W. Ladd (Eds.), Peer relationships in child development (pp. 15-45). New York: Wiley. 
614 Camiré, M., Forneris, T., Trudel, P., \& Bernard, D. (2011). Strategies for helping coaches

615

616

617

618

619

620

621

622

623

624

625

626

627

628

629

630

631

632

633

634

635

636

637

638 facilitate positive youth development through sport. Journal of Sport Psychology in Action, 2, 92. doi: 10.1080/21520704.2011.584246

Celeux, G., \& Soromenho, G. (1996). An entropy criterion for assessing the number of clusters in a mixture model. Journal of Classification, 13, 195-212.

Chan, D. K., Lonsdale, C., \& Fung, H. H. (2012). Influences of coaches, parents, and peers on the motivational patterns of child and adolescent athletes. Scandinavian Journal of Medicine \& Science in Sports, 22, 558-568. doi: 10.1111/j.1600-0838.2010.01277.x

Côté, J. (1999). The influence of the family in the development of talent in sport. Sport Psychologist, 13, 395-417.

Côté, J., Baker, J., \& Abernethy, B. (2003). From play to practice: A developmental framework for acquisition of expertise in team sports. In J. Starkes \& K. A. Ericsson (Eds.), Expert performance in sports: Advances in research on sport expertise (pp. 89-110). Champaign, IL: Human Kinetics.

Côté, J., \& Gilbert, W. (2009). An integrative definition of coaching effectiveness and expertise. International Journal of Sports Science \& Coaching, 4, 307-323.

Côte, J., \& Hay, J. (2002). Family influences on youth sport participation and performance. In J. M. Silva \& D. Stevens (Eds.), Psychological foundations of sport (pp. 503-519). Boston, MA: Allyn and Bacon.

Côté, J., \& Hay, J. (2002). Children's involvement in sport: A developmental perspective. In J. M. Silva \& D. E. Stevens (Eds.), Psychological foundations of sport (pp. 484-502). Boston, MA: Allyn and Bacon.

Crane, J., \& Temple, V. (2015). A systematic review of dropout from organized sport among children and youth. European Physical Education Review, 21, 114-131. doi: 10.1177/1356336x14555294 
Eime, R. M., Young, J. A., Harvey, J. T., Charity, M. J., \& Payne, W. R. (2013). A systematic review of the psychological and social benefits of participation in sport for children and adolescents: Informing development of a conceptual model of health through sport. The International Journal of Behavioral Nutrition and Physical Activity, 10, 1-21. doi: 10.1186/1479-5868-10-98

Fredricks, J. A., \& Eccles, J. S. (2005). Family socialization, gender, and sport motivation and involvement. Journal of Sport \& Exercise Psychology, 27, 3-31.

Friedman, H. L. (2013). Playing to win: Raising children in a competitive culture. Berkeley and Los Angeles: University of California Press.

Furman, W., \& Buhrmester, D. (1985). Children’s perceptions of the personal relationships in their social networks. Developmental Psychology, 21, 1016-1024.

Gearity, B. T., \& Murray, M. A. (2011). Athletes’ experiences of the psychological effects of poor coaching. Psychology of Sport and Exercise, 12, 213-221. doi: http://dx.doi.org/10.1016/j.psychsport.2010.11.004

Gould, D. (2007). Understanding attrition in children's sport. In D. Smith \& M. Bar-Eli (Eds.), Essential reading in sport and exercise psychology (pp. 401-411). Champaign, IL: Human Kinetics.

Gould, D., Collins, K., Lauer, L., \& Chung, Y. (2007). Coaching life skills through football: A study of award winning high school coaches. Journal of Applied Sport Psychology, 19, 16-37. doi: 10.1080/10413200601113786

Hall, M. S., Newland, A., Newton, M., Podlog, L., \& Baucom, B. R. (2016). Perceptions of the social psychological climate and sport commitment in adolescent athletes: A multilevel analysis. Journal of Applied Sport Psychology, 1-13. doi: 10.1080/10413200.2016.1174906 
663 Harter, S. (1985). Manual for the self-perception profile for children. Denver: University of

664

665

666

667

668

669

670

671

672

673

674

675

676

677

678

679

680

681

682

683

684

685

686 Denver.

Hayes, A. F., \& Preacher, K. J. (2014). Statistical mediation analysis with a multicategorical independent variable. British Journal of Mathematical and Statistical Psychology, 67, 451-470. doi: 10.1111/bmsp.12028

Hebert, J. J., Møller, N. C., Andersen, L. B., \& Wedderkopp, N. (2015). Organized sport participation is associated with higher levels of overall health-related physical activity in children (CHAMPS Study-DK). PLoS ONE, 10, 1-12. doi: 10.1371/journal.pone.0134621

Janssen, I., \& Leblanc, A. G. (2010). Systematic review of the health benefits of physical activity and fitness in school-aged children and youth. The International Journal of Behavioral Nutrition and Physical Activity, 7, 1-16. doi: 10.1186/1479-5868-7-40

Jowett, S., \& Ntoumanis, N. (2004). The coach-athlete relationship questionnaire (CART-Q): Development and initial validation. Scandinavian Journal of Medicine \& Science in Sports, 14, 245-257. doi: 10.1046/j.1600-0838.2003.00338.x

Jowett, S., \& Poczwardowski, A. (2007). Understanding the coach-athlete relationship. In S. Jowett \& D. Lavallee (Eds.), Social psychology in sport (pp. 3-14). Champaign, IL: Human Kinetics.

Keegan, R., Harwood, C. G., Spray, C. M., \& Lavallee, D. E. (2009). A qualitative investigation exploring the motivational climate in early career sports participants: Coach, parent and peer influences on sport motivation. Psychology of Sport \& Exercise, 10, 361-372. doi: 10.1016/j.psychsport.2008.12.003

Keegan, R., Spray, C., Harwood, C., \& Lavallee, D. (2010). The motivational atmosphere in youth sport: Coach, parent, and peer influences on motivation in specializing sport 
687

688

689

690

691

692

693

694

695

696

697

698

699

700

701

702

703

704

705

706

707

708

709

participants. Journal of Applied Sport Psychology, 22, 87-105. doi: $10.1080 / 10413200903421267$

Lafferty, M. E., \& Dorrell, K. (2006). Coping strategies and the influence of perceived parental support in junior national age swimmers. Journal of Sports Sciences, 24, 253259. doi: $10.1080 / 17461390500188702$

Lafrenière, M.-A. K., Jowett, S., Vallerand, R. J., \& Carbonneau, N. (2011). Passion for coaching and the quality of the coach-athlete relationship: The mediating role of coaching behaviors. Psychology of Sport \& Exercise, 12, 144-152. doi: 10.1016/j.psychsport.2010.08.002

Muthén, L. K., \& Muthén, B. O. (1998-2012). Mplus Users Guide. Seventh Edition. Los Angeles, CA: Muthén \& Muthén.

Ntoumanis, N., \& Biddle, S. J. H. (1999). A review of motivational climate in physical activity. Journal of Sports Sciences, 17, 643-665.

Nunnally, J. C. (1978). Psychometric Theory (2 ed.). New York: McGraw-Hill.

Nylund, K. L., Asparouhov, T., \& Muthen, B. O. (2007). Deciding on the number of classes in latent class analysis and growth mixture modeling: A monte carlo simulation study. Structural Equation Modeling: A Multidisciplinary Journal, 14, 535-569.

Olympiou, A., Jowett, S., \& Duda, J. L. (2008). The psychological interface between the coach-created motivational climate and the coach-athlete relationship in team sports. Sport Psychologist, 22, 423-438.

Pastor, D. A., Barron, K. E., Miller, B. J., \& Davis, S. L. (2007). A latent profile analysis of college students' achievement goal orientation. Contemporary Educational Psychology, 32, 8-47. doi: http://dx.doi.org/10.1016/j.cedpsych.2006.10.003 
Pelletier, L. G., Fortier, M. S., Vallerand, R. J., \& Brière, N. M. (2001). Associations among perceived autonomy support, forms of self-regulation, and persistence: A prospective study. Motivation and Emotion, 25, 279-306. doi: 10.1023/a:1014805132406

Quested, E., Ntoumanis, N., Viladrich, C., Haug, E., Ommundsen, Y., Van Hoye, A., . . . Duda, J. L. (2013). Intentions to drop-out of youth soccer: A test of the basic needs theory among European youth from five countries. International Journal of Sport and Exercise Psychology, 11, 395-407. doi: 10.1080/1612197x.2013.830431

Ram, N., \& Grimm, K. J. (2009). Growth mixture modeling: A method for identifying differences in longitudinal change among unobserved groups. International Journal of Behavioral Development, 33, 565-576.

Riley, A., \& Smith, A. L. (2011). Perceived coach-athlete and peer relationships of young athletes and self-determined motivation for sport. International Journal of Sport Psychology, 42, 115-133.

Rottensteiner, C., Konttinen, N., \& Laakso, L. (2015). Sustained participation in youth sports related to coach-athlete relationship and coach-created motivational climate. International Sport Coaching Journal, 2, 29-38.

Sánchez-Miguel, P. A., Leo, F. M., Sánchez-Oliva, D., Amado, D., \& García-Calvo, T. (2013). The importance of parents' behavior in their children’s enjoyment and amotivation in sports. Journal of Human Kinetics, 36, 169-177. doi: 10.2478/hukin2013-0017

Sarrazin, P., Vallerand, R., Guillet, E., Pelletier, L., \& Cury, F. (2002). Motivation and dropout in female handballers: A 21-month prospective study. European Journal of Social Psychology, 32, 395-418. doi: 10.1002/ejsp.98

Scanlan, T. K., Carpenter, P. J., Lobel, M., \& Simons, J. P. (1993). Sources of enjoyment for youth sport athletes. Pediatric Exercise Science, 5, 275-285. 
Scanlan, T. K., \& Simons, J. P. (1992). The construct of sport enjoyment. In G. C. Roberts (Ed.), Motivation and exercise (Vol. 11, pp. 65-83). Champaign IL: Human Kinetics.

Scanlan, T. K., Simons, J. P., Carpenter, P. J., Schmidt, G. W., \& Keeler, B. (1993). The Sport Commitment Model: Measurement development for the youth-sport domain. Journal of Sport \& Exercise Psychology, 15, 16-38.

Sheridan, D., Coffee, P., \& Lavallee, D. (2014). A systematic review of social support in youth sport. International Review of Sport and Exercise Psychology, 7, 198-228. doi: 10.1080/1750984x.2014.931999

Smith, A. L. (1999). Perceptions of peer relationships and physical activity participation in early adolescence. Journal of Sport \& Exercise Psychology, 21, 329-350.

Smith, A. L., Ullrich-French, S., Walker, E., \& Hurley, K. S. (2006). Peer relationship profiles and motivation in youth sport. Journal of Sport \& Exercise Psychology, 28, 362-382.

Sullivan, H. S. (1953). The interpersonal theory of psychiatry. New York, NY: W. W. Norton.

Ullrich-French, S., \& Smith, A. L. (2006). Perceptions of relationships with parents and peers in youth sport: Independent and combined prediction of motivational outcomes. Psychology of Sport \& Exercise, 7, 193-214. doi: 10.1016/j.psychsport.2005.08.006

Ullrich-French, S., \& Smith, A. L. (2009). Social and motivational predictors of continued youth sport participation. Psychology of Sport \& Exercise, 10, 87-95. doi: 10.1016/j.psychsport.2008.06.007

Van Yperen, N. W. (1995). Interpersonal stress, performance-level, and parental support: A longitudinal-study among highly skilled young soccer players. Sport Psychologist, 9, 225-241. 
759

760

761

762

763

764

765

766

767

768

769

770

771

772

773

774

775

776

777

Vella, S. A., Cliff, D. P., Magee, C. A., \& Okely, A. D. (2014). Sports participation and parent-reported health-related quality of life in children: Longitudinal associations. The Journal of Pediatrics, 164, 1469-1474. doi: 10.1016/j.jpeds.2014.01.071

Vella, S. A., Cliff, D. P., Magee, C. A., \& Okely, A. D. (2015). Associations between sports participation and psychological difficulties during childhood: A two-year follow up. Journal of Science and Medicine in Sport, 18, 304-309. doi: 10.1016/j.jsams.2014.05.006

Vella, S. A., Cliff, D. P., \& Okely, A. D. (2014). Socio-ecological predictors of participation and dropout in organised sports during childhood. International Journal of Behavioral Nutrition and Physical Activity, 11, 62-71. doi: 10.1186/1479-5868-11-62

Vella, S. A., Oades, L. G., \& Crowe, T. P. (2013). The relationship between coach leadership, the coach-athlete relationship, team success, and the positive developmental experiences of adolescent soccer players. Physical Education and Sport Pedagogy, 18, 549-561. doi: 10.1080/17408989.2012.726976

Weiss, M. R., \& Smith, A. L. (1999). Quality of youth sport friendships: Measurement development and validation. Journal of Sport \& Exercise Psychology, 21, 145-166.

Wiese-Bjornstal, D. M., Lavoi, N. M., \& Omli, J. (2009). Child and adolescent development and sport participation. In B. W. Brewer (Ed.), Sport Psychology (pp. 97-112). Oxford, UK: Wiley-Blackwell. 